\title{
Article \\ Geometrical Optimization of a Venturi-Type Microbubble Generator Using CFD Simulation and Experimental Measurements
}

\author{
Dillon Alexander Wilson ${ }^{1}$, Kul Pun ${ }^{1}$ (D) Poo Balan Ganesan ${ }^{2}$ and Faik Hamad 1,*(D) \\ 1 School of Computing, Engineering \& Digital Technologies, Teesside University, Middlesbrough, \\ Tees Valley TS1 3BX, UK; S6013568@tees.ac.uk (D.A.W.); k.pun@tees.ac.uk (K.P.) \\ 2 Department of Mechanical Engineering, University of Malaya, Kuala Lumpur 50603, Malaysia; \\ poo_ganesan@um.edu.my \\ * Correspondence: F.Hamad@tees.ac.uk
}

Citation: Wilson, D.A.; Pun, K.; Ganesan, P.B.; Hamad, F. Geometrical Optimization of a Venturi-type Microbubble Generator using CFD Simulation and Experimental Measurements. Designs 2021, 5, 4. https://doi.org/10.3390/designs5 010004

Received: 12 October 2020 Accepted: 30 December 2020 Published: 7 January 2021

Publisher's Note: MDPI stays neutral with regard to jurisdictional clai$\mathrm{ms}$ in published maps and institutional affiliations.

Copyright: (C) 2021 by the authors. Licensee MDPI, Basel, Switzerland. This article is an open access article distributed under the terms and conditions of the Creative Commons Attribution (CC BY) license (https:// creativecommons.org/licenses/by/ $4.0 /)$.

\begin{abstract}
Microbubble generators are of considerable importance to a range of scientific fields from use in aquaculture and engineering to medical applications. This is due to the fact the amount of sea life in the water is proportional to the amount of oxygen in it. In this paper, experimental measurements and computational Fluid Dynamics (CFD) simulation are performed for three water flow rates and three with three different air flow rates. The experimental data presented in the paper are used to validate the CFD model. Then, the CFD model is used to study the effect of diverging angle and throat length/throat diameter ratio on the size of the microbubble produced by the Venturi-type microbubble generator. The experimental results showed that increasing water flow rate and reducing the air flow rate produces smaller microbubbles. The prediction from the CFD results indicated that throat length/throat diameter ratio and diffuser divergent angle have a small effect on bubble diameter distribution and average bubble diameter for the range of the throat water velocities used in this study.
\end{abstract}

Keywords: CFD simulation; venture-type microbubble generator; geometrical optimization; bubble breakup

\section{Introduction}

One of the most common uses of microbubbles in industry is water-waste treatment and disinfection [1-3] which is done via microbubble aeration. When microbubbles are introduced into the water pollutants, the small particles as well as bacteria attach themselves to the bubbles, which are then brought to the surface as the bubble rises to the surface of the water. At this point, the foam of pollutants and sediments including the bacteria can then be removed from the water leaving a clean disinfected volume of water behind. Applications of microbubbles can also be found in aquafarming as well as a wide range of medical applications.

In aquafarming, there is the potential to significantly increase the farm's production through the application of microbubble generators that increase dissolved oxygen which improves sea life metabolism. Aquafarming therefore has the potential to significantly increase the amount of seafood collected from ocean farms through the application of microbubble generators [4].

In medicine, microbubbles are commonly used as a contrasting agent in ultrasound scans. Microbubbles resonate when exposed to an ultrasound beam, they quickly expand or contract in response to the pressure of the ultrasound wave. When the microbubble is vibrating at very high frequencies, they are much more reflective than normal human tissue, allowing good quality enhanced grey scaled images to be produced [5].

Bubbles have been classified into three different categories based on the diameter of the bubble. The first category is a macrobubble, any bubble with a diameter greater than 
$100 \mu \mathrm{m}$ falls into this category and this range captures most bubbles. The next category is microbubbles, these bubbles range from $0.2 \mu \mathrm{m}<\mathrm{d}<100 \mu \mathrm{m}$. The final category is nanobubbles, this category includes any bubble under $0.2 \mu \mathrm{m}$ in diameter. The amount of dissolved oxygen released into water has strong relationship with the diameter of the bubbles. Nanobubbles can stay in water for large durations of time before collapsing due to large internal pressure [6]. On the opposite end of the spectrum a macrobubble has a high expansion rate and as a result oxygen does not have enough time to defuse into the water. Microbubbles expand at a reduced rate when compared to macrobubbles, as a result this gives the oxygen more time to diffuse into the water. Additionally, microbubbles maintain a lower internal pressure when compared to nanobubbles. This ensures the bubble diffuses into the water instead of potentially persisting indefinitely like nanobubbles [7]. From the above information it is clear to see why industrial applications focus on the use of microbubbles for water oxygenation and why this study of bubble generators will focus on producing bubbles in the micro range.

There are three different methods used to produce microbubbles. One method is by delivering a stream of air under low pressure, which leads to bubbles breaking off the airstream due to mechanical vibrations. Another method of producing microbubbles is by using powerful ultrasound waves. Ultrasound waves are used to induce cavitation at points of high rarefaction in the liquid. The final method is by compression of a gas stream so that it dissolves the gas into the liquid. The gas is injected into the liquid through a specially designed nozzle, this nozzle is designed to produce small bubbles in the nanobubble region. These bubbles will then grow into larger bubbles through the rapid dissolution of saturated liquid. The compression and ultrasound methods require greater power usage when compared with the low-pressure air stream method. However, the low-pressure air stream method achieves less desirable results regarding the mean bubble diameter in the bubble distribution. This can be due to issues in bubble dispersion and air phase hold up, and therefore the compression method of microbubble generation is used as the initial design concept for this analysis [8].

In recent years, a range of different designs of microbubble generators have been used to produce smaller microbubbles, the researchers studying the effect of converging angle, throat length, throat diameter, and diverging angle to understand the geometrical effect on bubble diameters. Their results indicated that further research is required to understand the effect of changing the throat length/throat diameter ratios and the effect this has on the bubble sizing [9-11]. Hence, the purpose of this paper is twofold. The first objective is to create a CFD model in Fluent with the same dimensions of the Venturi used in the experimental investigation. The experimental data produced from lab measurements are used to validate the CFD model. The second objective is to use the validated model to study the effect of diverging angle $(\beta)$ and throat length/throat diameter $(1 / \mathrm{d})$ on bubble diameter at the exit section.

\section{Experimental}

Figure 1a present a schematic diagram of the experimental facility and Figure $1 \mathrm{~b}$ shows a three-dimensional (3-D) photo for test ring. It consists of a water tank of $440 \mathrm{~mm}$ height, $380 \mathrm{~mm}$ width, and $275 \mathrm{~mm}$ length connected to a $0.665 \mathrm{~kW}$ pump producing a water flow rate more than $15 \mathrm{~L} / \mathrm{min}$ when no air is injected in the system. The microbubble generator was connected to the right wall of the tank, and its inlet presented a T-junction where air was supplied and mixed with water. A $20 \mathrm{~W}$ halogen lamp was located on the opposite side with respect to the water tank to illuminate the field of view of a SONY DSC-RX10 camera. Videos were recorded for each measurement at 25 frames/s to ensure that the same bubble was not processed more than once. In order to improve image quality, the water tank was obscured while diffused light was allowed through a $1 \mathrm{~mm}$ strip. In this way, microbubbles could be better focused whereas quantities such as working distance, focal length, and depth of field were known and fixed. Tests were performed by fixing the water flow rate at 8.21 and $13.3 \mathrm{~L} / \mathrm{min}$ and variable air flow rates that gave volumetric 
qualities of $0.05,0.1$, and 0.2. The time interval between each test was large enough to allow all microbubbles to disappear from the field of view. Additionally, microbubbles were recorded after a certain time the microbubble generator was off to achieve steady state conditions.

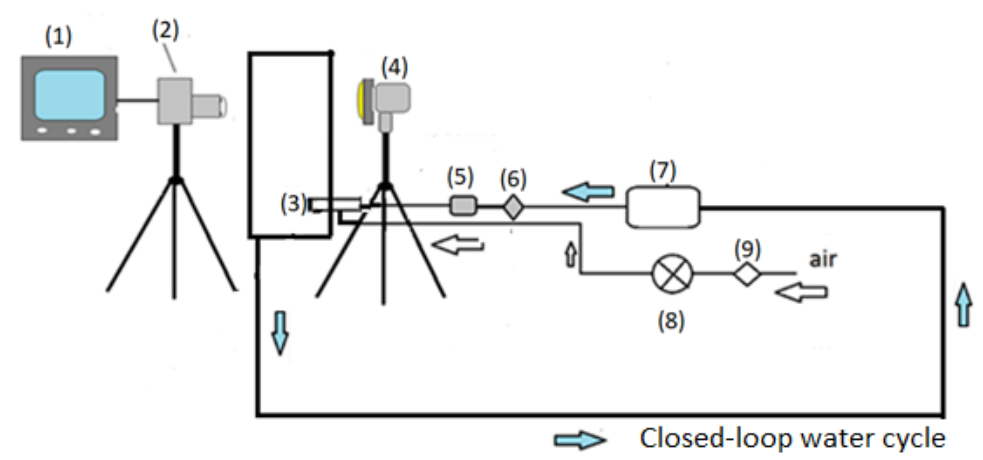

(a)

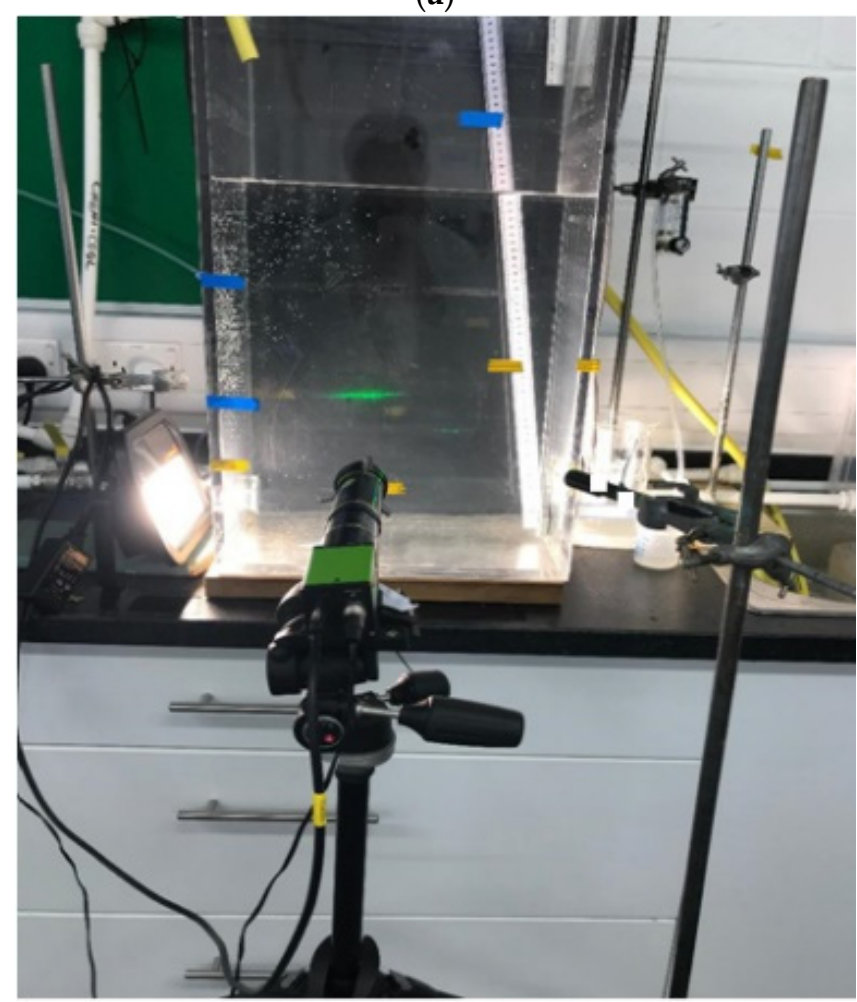

(b)

Figure 1. (a) Schematic diagram of the test rig. (1) Personal computer, (2) high-resolution camera, (3) microbubble generator, (4) halogen lamp, (5) water pressure gauge, (6) water pump, (7) flow control valve, (8) air pressure gauge, (9) needle valve. (b) Photo of the test rig at Teesside University.

The bubbles were processed with in-focus (clear and sharp focus bubble images). Figure 2 shows the location of the collected images in the water tank. The level of the camera was adjusted to be $19-20.5 \mathrm{~cm}$ above the microbubble entrance to minimize the effect of turbulence generated by the jet of bubbles. A scale image was taken before each experiment to be used when converting bubble diameters from pixel width to $\mu \mathrm{m}$. The camera was located at $16 \mathrm{~mm}$ from the front wall of the tank, the frame. The number of frames was 25 per second. 


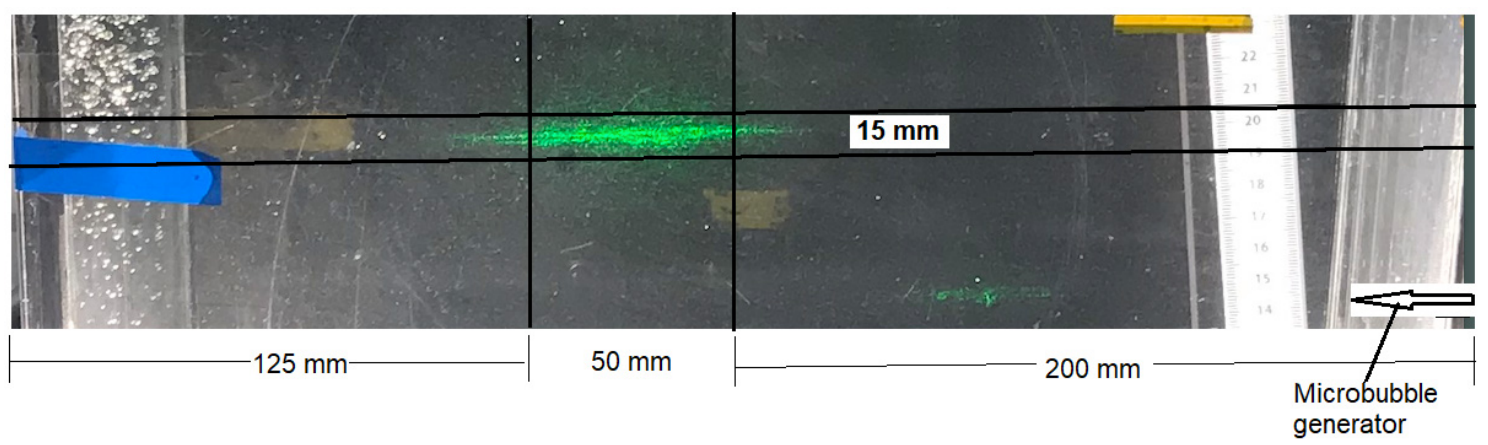

Figure 2. The front view of the water tank to show the locations of microbubble generator and the location of the images collected in the water tank.

An image analysis procedure was developed to extract bubble diameter distributions recorded by the high-speed camera by Basso et al. [12]. An image analysis procedure was developed to extract bubble diameter distributions from video frames recorded by the high-resolution camera. A code was also developed by Basso et al. [12]) in MATLAB 2016a software for binary image processing and cross correlation. Binary processing was divided into three different stages and includes morphological operations such as area opening, median filtering, thinning, thickening, image filling, and skeletonization. In each operation, pixels were removed or added with the final aim of maximizing the correlation coefficient between the current image with the original movie frame. Furthermore, median filtering was crucial for edge detection as it can remove image noise while preserving the contour of binary objects. Size of the cell for median filter is also selected on an image correlation basis. The bubble diameter was extracted through Hough transform where a circle parameter becomes a known variable when a number of points falls within its parameters [13].

\section{CFD Model and Simulation}

\subsection{Geometry Setup}

Figure 3 presents the two-dimensional (2-D) sketch of the microbubble generator used in this study which mimics the one used for experimental measurements. The internal flow volume that is used for modeling on Ansys Fluent can be seen in Figure 4. The main dimensions of this baseline generator are given in Table 1 . The dimensions of the venturi device were determined earlier by Basso et al. [7,12] during the initial stage of building the experimental rig. The dimensions in the table were based on the literature review, CFD study, and the experimental measurements in the lab.

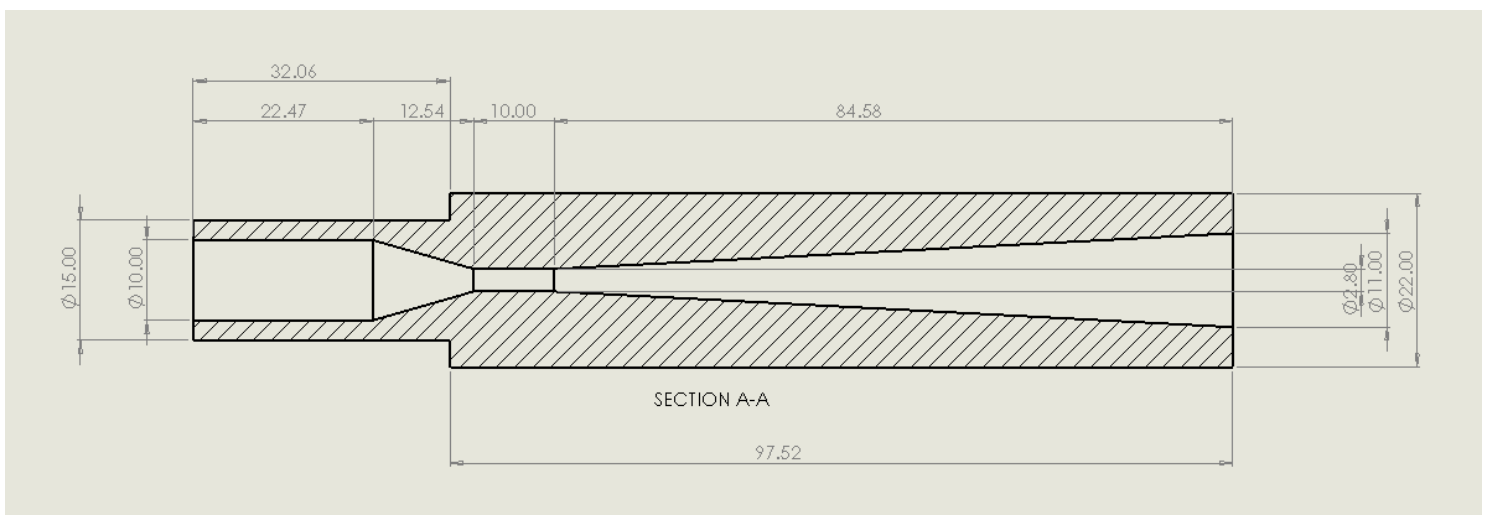

Figure 3. The 2-D sketch of Venturi-type baseline microbubble Generator model. 


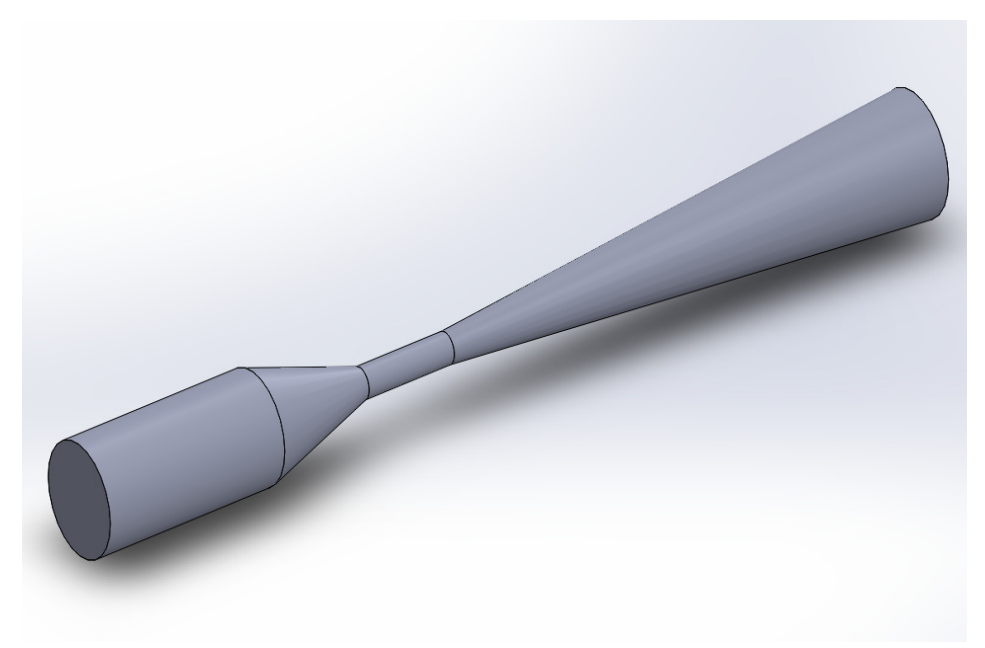

Figure 4. The microbubble Generator computational domain.

Table 1. The dimensions for experimental generator (baseline case).

\begin{tabular}{cc}
\hline Generator Part & Dimension \\
\hline Generator inlet diameter & $10 \mathrm{~mm}$ \\
Generator inlet length & $20.47 \mathrm{~mm}$ \\
Throat diameter $(\mathrm{d})$ & $2.8 \mathrm{~mm}$ \\
Throat length $(\mathrm{l})$ & $10 \mathrm{~mm}$ \\
Diffuser outlet diameter & $11 \mathrm{~mm}$ \\
Diffuser length & $55 \mathrm{~mm}$ \\
Diffuser divergent angle $(\beta)$ & $4.26^{\circ}$ \\
Pre-throat length $(\mathrm{v})$ & $12.54 \mathrm{~mm}$ \\
Pre-throat angle $(\alpha)$ & $16.02^{\circ}$ \\
\hline
\end{tabular}

To get useful data from the model, the setting up of the mesh was an important factor, therefore once the internal flow volume was imported from Solidworks and the named selections of the volume defined such as the inlet, outlet, and walls, an appropriate method was selected. For this model, it was determined that an automatic method could be used for the selected volume with an element size of $0.5 \mathrm{~mm}$ across the model as this satisfied computer capabilities and requirements of the model. Despite an automatic method constructing, the mesh with an element size of $0.5 \mathrm{~mm}$ across the mesh further refinement was made on the outlet surface of the generator, as this was an area of high interest. Therefore, a face sizing refinement was made on this surface reducing the element size to $0.25 \mathrm{~mm}$. The overall view of the mesh with the refined mesh distribution across the outlet shown is shown in Figure 5.

The meshing produced for the computational domain was based on element size of $0.5 \mathrm{~mm}$ across the geometry with a further refinement to $0.25 \mathrm{~mm}$ made at the outlet of the geometry (Venturi). A smooth transition was selected for the inflation resulting in a transition ratio of 0.2272 , growth rate of 1.2 , and the maximum number of layers is 5 . This method produced 40,539 nodes and 205,368 elements across the small geometry. The mesh skewness was checked to confirm the good quality of the mesh of the computational domain. It was found that the average skewness was of 0.22802 , minimum value of $9.0576 \times 10^{-4}$, and a maximum value of 0.78786 . These values are below the acceptable limit of 0.85 in Fluent which indicated that the mesh quality was good and suitable to carry out the simulation. 


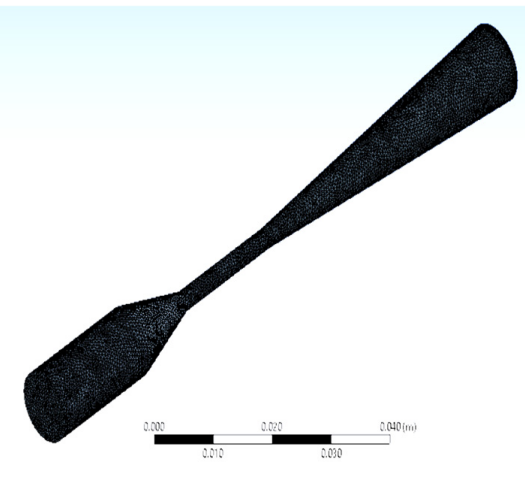

(A)

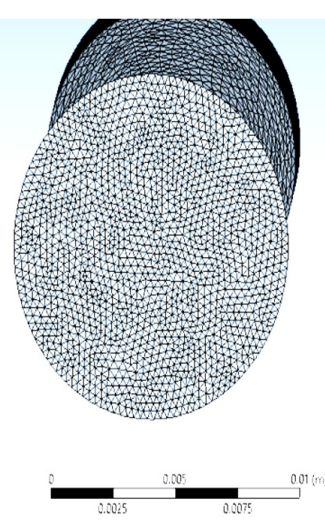

(B)

Figure 5. (A) Mesh of the computational domain, (B) mesh of the outlet section.

\subsection{The Mathematical Model}

In this study, a combination of Eulerian and Langrangian approaches was introduced and used in order to study the multiphase behavior of fluid passing through the Venturi, as the equation for water and gas phases were solved by using Eulerian-Lagrangian framework. Numerical simulations were carried out using ANSYS Fluent. The conservation equations for both phases are given hereafter.

\subsubsection{Continuous Phase}

The equations for conservation of mass, momentum-with an appropriate turbulence model-and energy are used. The model was devised for three-dimensional, steady, turbulent, incompressible, and axisymmetric flow with constant properties [14].

Continuity equation

$$
\frac{\partial\left(\rho u_{i}\right)}{\partial x_{i}}=S_{m}
$$

Momentum equations

$$
\frac{\partial\left(\rho u_{i} u_{j}\right)}{\partial x_{j}}=-\frac{\partial p}{\partial x_{i}}+\frac{\partial}{\partial x_{j}}\left[\mu\left(\frac{\partial u_{i}}{\partial x_{j}}+\frac{\partial u_{j}}{\partial x_{i}}\right)\right]+\frac{\partial\left(-\rho \overline{u_{i}^{\prime} u_{j}^{\prime}}\right)}{\partial x_{j}}+\rho g+F
$$

Energy equation

$$
\frac{\partial\left(u_{i} \rho E\right)}{\partial x_{j}}=\frac{\partial}{\partial x_{j}}\left[\left(k_{f}+\frac{c_{p} \mu_{t}}{P r_{t}}\right) \frac{\partial T_{i}}{\partial x_{j}}\right]+S_{h}
$$

Reynolds stresses are modeled using the Boussinesq approximation [14].

$$
\frac{\partial\left(-\rho \overline{u_{i}^{\prime} u_{j}^{\prime}}\right)}{\partial x_{j}}=\mu_{t}\left(\frac{\partial u_{i}}{\partial x_{j}}+\frac{\partial u_{j}}{\partial x_{i}}\right)-\frac{2}{3} \rho k \delta_{i j}
$$

Turbulence is modeled through the Standard k- $\varepsilon$ set in Equations (5) and (6), where eddy viscosity adds to the fluid viscosity, directly proportional to the square of the turbulence kinetic energy:

$$
\begin{aligned}
& \mu_{\text {eff }}=\mu+\mu_{\mathrm{t}} \\
& \mu_{\mathrm{t}}=\mathrm{C}_{\mu} \rho \frac{\mathrm{k}^{2}}{\varepsilon}
\end{aligned}
$$




\subsubsection{Bubble Equation}

Prediction of the particle trajectory is based on integrating the force balance on the particle, which is based on Lagrangian formulation $[15,16]$. The effect of different forces on discrete particle motion have been studied in detail by Stakic et al. [16]. The main conclusion was that the pressure forces, the forces due to the particle "added" mass, as well as Basset and Magnus forces can be neglected, and the equation of droplet/particle motion can be simplified to include drag force and gravity. In addition to the recommendation by Stakic et al. [16] and other author, the droplet/particles in this investigation are very small and the surface forces which depend on the surface area are negligible. The balance of inertia, drag, and gravitational forces acts on the particle in the $x$ direction as [14],

$$
\begin{gathered}
\frac{d u_{p}}{d t}=F_{D}\left(u-u_{p}\right)+\frac{g_{x}\left(\rho_{p}-\rho\right)}{\rho_{p}} \\
F_{D}=\frac{18 \mu}{\rho_{p} d_{p}^{2}} \frac{C_{D} R e}{24}
\end{gathered}
$$

where the term $F_{D}\left(u-u_{p}\right)$ is the drag force per unit particle mass and $F_{D}$ the drag force encountered by the particle. Furthermore, $u$ is the air velocity, $C_{D}$ the drag coefficient, $u_{p}$ is the particle velocity, $\mu$ is the air viscosity, $\rho$ is the air density, $\rho_{p}$ the particle density, and $d_{p}$ is the particle diameter. Re is the relative Reynolds number which is defined in Equation (9).

$$
\operatorname{Re}=\frac{\rho \mathrm{d}_{\mathrm{p}}\left|\mathrm{u}_{\mathrm{p}}-\mathrm{u}\right|}{\mu}
$$

The main physical properties and boundary conditions of the model setup are given in Tables 2 and 3. The dimensions of microbubble generator in Table 1, the physical properties in Table 2, and the boundary conditions in Table 3 were the data used for baseline case which were used to study the effect of throat length/throat diameter ratio $(1 / d)$ and diffuser divergent angle on bubble diameter.

Table 2. The physical properties of water and air.

\begin{tabular}{cc}
\hline Fluid Property & Value and Unit \\
\hline Gas (air) density & $1.225 \mathrm{~kg} / \mathrm{m}^{3}$ \\
Gas (air) dynamic viscosity & $1.7894 \times 10^{-0.5} \mathrm{~kg} / \mathrm{m} \cdot \mathrm{s}$ \\
Initial bubble diameter (average) & $100 \mu \mathrm{m}$ \\
Liquid (water) density & $998.2 \mathrm{~kg} / \mathrm{m}^{3}$ \\
Liquid (water) dynamic viscosity & $0.001003 \mathrm{~kg} / \mathrm{m} \cdot \mathrm{s}$ \\
Gravity acceleration & $-9.81 \mathrm{~m} / \mathrm{s}^{2}$ \\
\hline
\end{tabular}

Table 3. Boundary conditions for baseline case.

\begin{tabular}{ccc}
\hline Boundary Name & Liquid & Gas \\
\hline \multirow{2}{*}{ Inlet } & Volumetric quality 0.9988 & Volumetric quality 0.012 \\
& Flow rate $8.21 \mathrm{~L} / \mathrm{min}$ & Flow rate $0.1 \mathrm{~L} / \mathrm{min}$ \\
\hline
\end{tabular}

For this simulation, a multiphase Eulerian-Lagrangian model was used with two phases with the volumetric quality parameters defined implicitly in order to model the multiphase flow accurately. Water was the primary phase and air was the secondary phase. The standard k-epsilon turbulence model with standard wall functions was used. The discrete phase model (DPM) was used for the tracking of bubbles and their diameters as they moved through the generator. The Rosin-Rammler distribution for the air injected with the water at a temperature of $288 \mathrm{k}$ with a velocity of $1.763 \mathrm{~m} / \mathrm{s}$ and a flow rate of 
$2.041 \times 10^{-6} \mathrm{~kg} / \mathrm{s}$. A time step size of $0.001 \mathrm{~s}$, with 15 iterations per time step for 1500 time were used.

To validate the numerical model used in the CFD simulation, the experimental data were collected from the microbubble generator tested in the fluid lab. The experimental data for water and air flow rates were used as boundary conditions for CFD simulation. Once the CFD model was validated with experimental data, it was used to produce data from the microbubble generator with different diverging angle and $\mathrm{l} / \mathrm{d}$ ratios.

\section{Results and Discussion}

\subsection{Effect of Flow Rate and Volumetric Quality}

For an accurate comparison to be made between the experimental measurements and the predictions from the model, the flow rates and volumetric qualities tested in the physical experiment were then setup in the models. The flow rates and volumetric qualities tested are given in Table 4.

Table 4. The water and air flow rates used to validate the model.

\begin{tabular}{|c|c|c|c|c|}
\hline \multirow[b]{2}{*}{ Boundary Name } & \multicolumn{4}{|c|}{ Flow Conditions } \\
\hline & Water Flow Rate (L/min) & Throat Reynolds Number & Air Flow Rate (L/min) & Volumetric Quality (\%) \\
\hline \multirow{9}{*}{ Inlet } & \multirow{3}{*}{13.3} & \multirow{3}{*}{100,800} & 0.05 & 0.375 \\
\hline & & & 0.1 & 0.75 \\
\hline & & & 0.2 & 1.48 \\
\hline & \multirow{3}{*}{8.21} & \multirow{3}{*}{62,200} & 0.05 & 0.61 \\
\hline & & & 0.1 & 1.22 \\
\hline & & & 0.2 & 2.41 \\
\hline & \multirow{3}{*}{1.22} & \multirow{3}{*}{9250} & 0.00732 & 0.61 \\
\hline & & & 0.01464 & 1.186 \\
\hline & & & 0.02928 & 2.344 \\
\hline
\end{tabular}

Data from the physical experiments suggest that there is a correlation between air flow rates and average bubble diameter as shown in Figures 6a and 7. It can be observed that an air flow rate of $0.05 \mathrm{~L} / \mathrm{min}$ produced the smallest mean bubbles diameters in both cases. Furthermore, the largest air flow rates of $0.2 \mathrm{~L} / \mathrm{min}$ produced the largest average bubble diameters in both cases. The equivalent flow conditions were created in the CFD model and the results can be seen in Figures 6a and 7 as well.

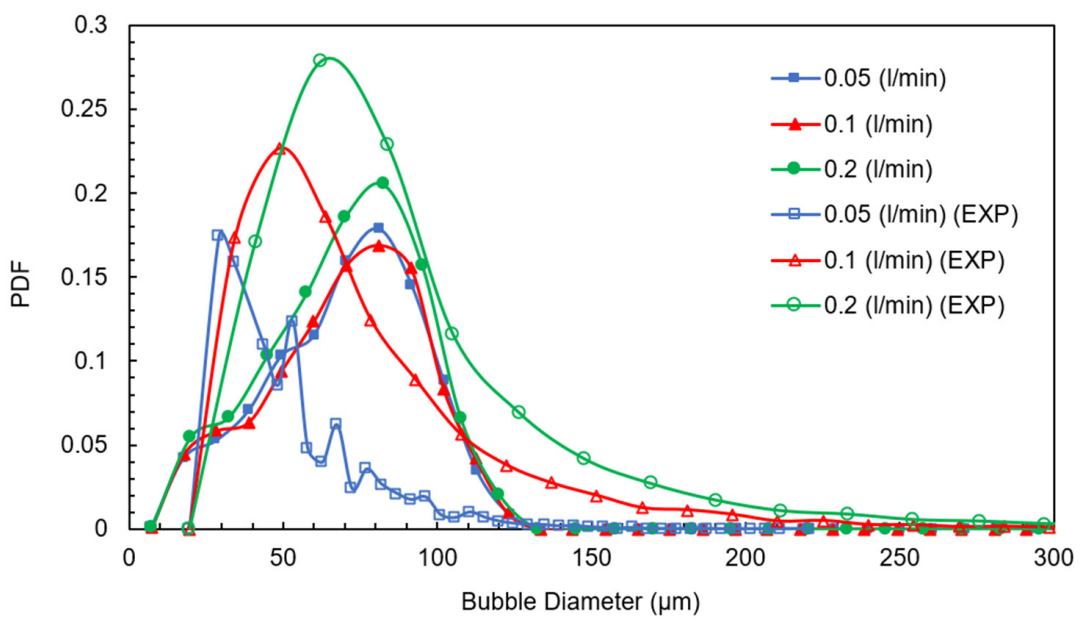

(a)

Figure 6. Cont. 


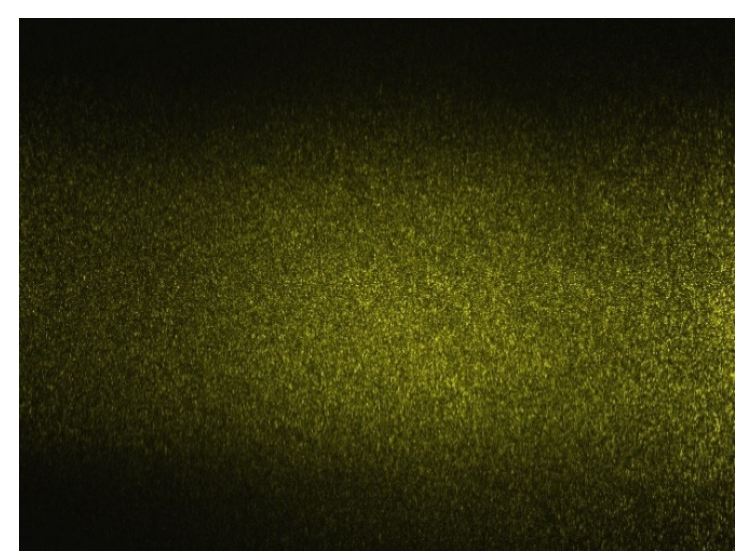

$8.21 \mathrm{~L} / \mathrm{min}-0.05 \mathrm{l} / \mathrm{m}$

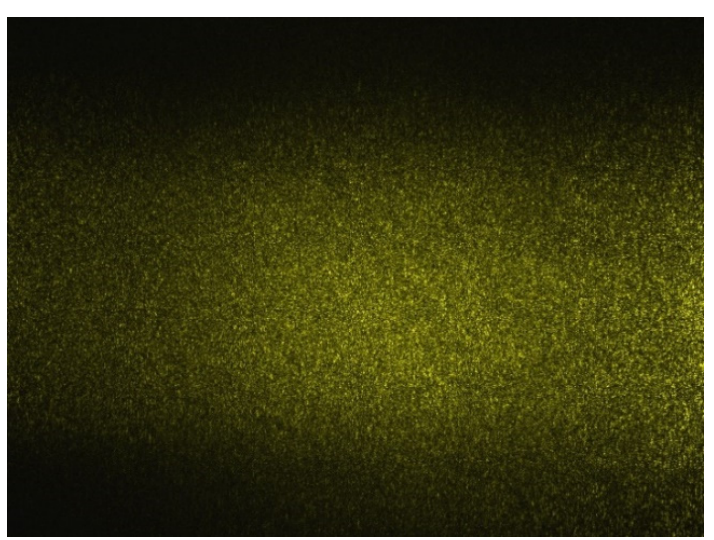

$8.21 \mathrm{~L} / \mathrm{min}-0.1 \mathrm{l} / \mathrm{m}$

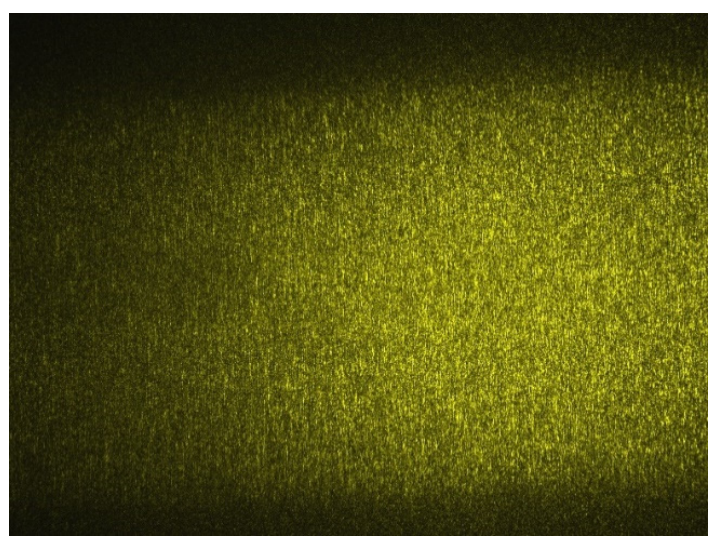

$8.21 \mathrm{~L} / \mathrm{min}-0.2 \mathrm{l} / \mathrm{m}$

(b)

Figure 6. (a) Distribution of bubble diameters at different air volume flow rate (water flow rate $=8.21 \mathrm{~L} / \mathrm{min}$ ) (experimental and CFD). Average diameter: $0.05 \mathrm{~L} / \mathrm{min}-64.8 \mu \mathrm{m}$ (CFD), $0.1 \mathrm{~L} / \mathrm{min}-64.9 \mu \mathrm{m}$ (CFD), $0.2 \mathrm{~L} / \mathrm{min}-63.9 \mu \mathrm{m}$ (CFD), $0.05 \mathrm{~L} / \mathrm{min}-$ $45.6 \mu \mathrm{m}$ (Exp.), 0.1 L/min-57.7 $\mu \mathrm{m}$ (Exp.), 0.2 L/min-65.1 $\mu \mathrm{m}$ (Exp.). (Throat Reynolds number $(\operatorname{Re})=62,200) ;(\mathbf{b})$ The images from experimental measurements for water flow rate of $8.21 \mathrm{~L} / \mathrm{min}$ and different air flow rates $(0.05 \mathrm{~L} / \mathrm{min}, 0.1 \mathrm{~L} / \mathrm{min}$, $0.2 \mathrm{~L} / \mathrm{min})$.

CFD data show that the volumetric quality of air has a small effect on the average bubbles diameters produced at the outlet of the microbubble generator as shown in Figures $6 \mathrm{a}$ and 7. The results in both Figures 6a and 7 display a very small differences in bubble mean diameter and probability density function (pdf) distribution with change in the air volumetric qualities. Figure $6 \mathrm{~b}$ presents the images from experimental measurements for water flow rate of $8.21 \mathrm{~L} / \mathrm{min}$ and different air flow rates $(0.05 \mathrm{~L} / \mathrm{min}, 0.1 \mathrm{~L} / \mathrm{min}$, $0.2 \mathrm{~L} / \mathrm{min}$ ). As the microbubbles were very small and a scale image was taken before each experiment to be used when converting bubble diameters from pixel width to $\mu \mathrm{m}$, the difference may not be observed from the images. However, the image for air flow rate of $0.2 \mathrm{~L} / \mathrm{min}$ shows a larger microbubble.

In order to examine the effect of low water flow rate on microbubble size, a CFD simulation was performed for flow rate of $1.22 \mathrm{~L} / \mathrm{min}$. It can be seen from Figure 8 that this flow rate produced larger mean bubbles diameter compared to the other two cases with higher flow rates. It also shows smaller volumetric qualities of air produced lower average bubble diameters at the outlet as we observed from present experimental data. The data at low water velocity (low Re) show that CFD will give a similar trend to experimental results for low Re. However, these data do suggest that there is a correlation between higher water flow rates and smaller average bubble diameters at the outlet, which confirms what was observed in the experiments. 


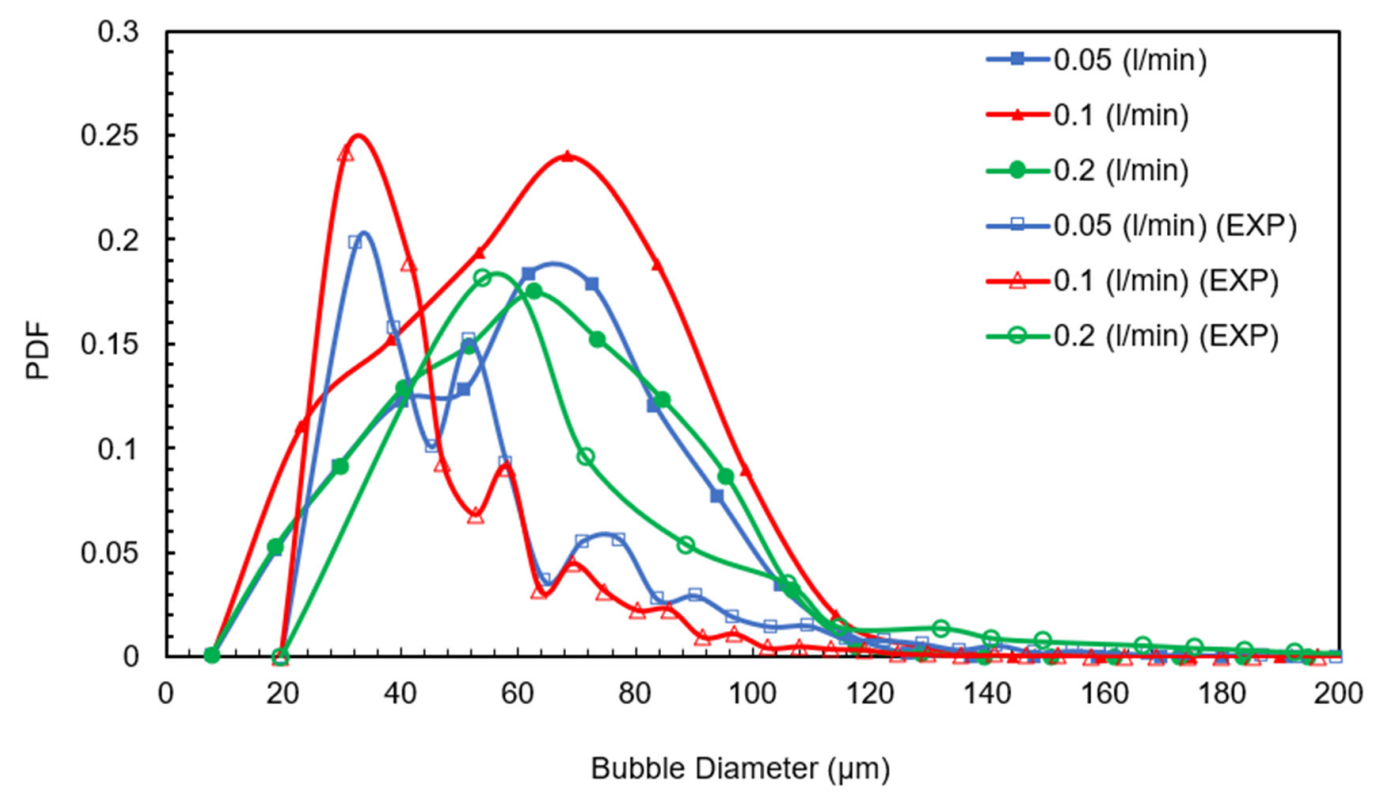

Figure 7. Distribution of bubble diameters at different air volume flow rate (water flow rate $=13.3 \mathrm{~L} / \mathrm{min})($ experimental and CFD). Average diameter: $0.05 \mathrm{~L} / \mathrm{min}-56.2 \mu \mathrm{m}$ (CFD), $0.1 \mathrm{~L} / \mathrm{min}-54.8 \mu \mathrm{m}$ (CFD), $0.2 \mathrm{~L} / \mathrm{min}-56.2 \mu \mathrm{m}(\mathrm{CFD}), 0.05 \mathrm{~L} / \mathrm{min}-$ $39.3 \mu \mathrm{m}$ (Exp.), $0.1 \mathrm{~L} / \mathrm{min}-46.2 \mu \mathrm{m}$ (Exp.), $0.2 \mathrm{~L} / \mathrm{min}-50.66 \mu \mathrm{m}$ (Exp.). (Throat Reynolds number $(\operatorname{Re})=100,800)$.

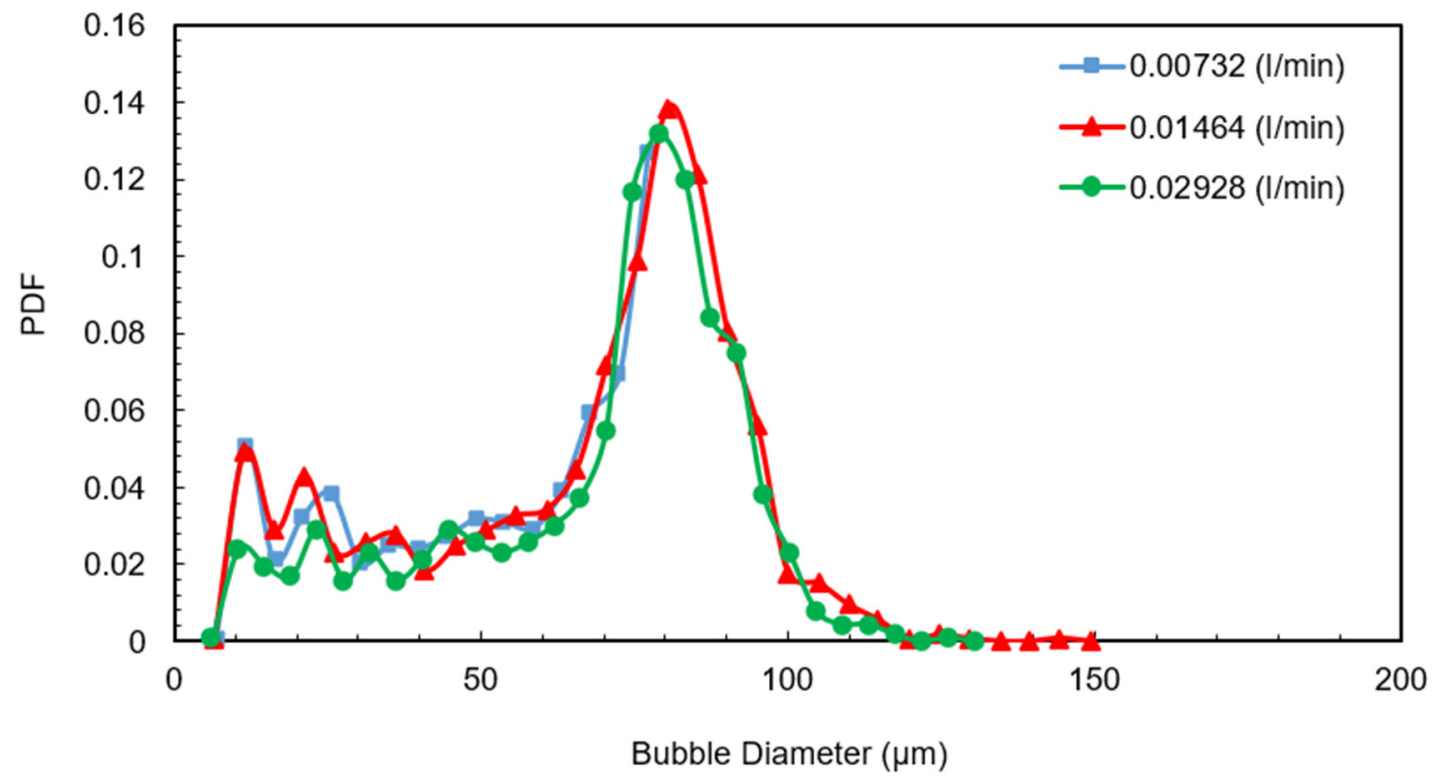

Figure 8. Distribution of bubble diameters at different air volume flow rate (water flow rate $=1.22 \mathrm{~L} / \mathrm{min}$ ) (CFD only). Average diameter: 0.05 L/min-63.6 $\mu \mathrm{m}$ (CFD), 0.1 L/min-64.1 $\mu \mathrm{m}$ (CFD), $0.2 \mathrm{~L} / \mathrm{min}-66.9 \mu \mathrm{m}$ (CFD). (Throat Reynolds number $(\operatorname{Re})=9250)$.

In general, experimental data display a greater range of bubbles diameters during testing whereas CFD data display a smaller range and a smaller minimum diameter recorded. Furthermore, all flow rates and air volumetric qualities tested produced a good uniform distribution of bubbles across the outlet of the base dimension microbubble generator as shown in Figure 9. The uneven distribution for all cases may be attributed to turbulence, breakage, coalescence, and cavitation according to Mingda et al. [11], which led to a secondary flow in a form of circulation in the diffuser section as shown in the velocity vectors given in Figure 10. The contours show a reverse flow in lower region while the flow in the upper region accelerated in the upper region. This recirculation process in the 
diffuser was also highlighted by Hang et al. [17] as the key role in bubble deformation and breakup. It not only led to the increase of turbulence dissipation rate but also prolonged the residence time of bubble in the diffuser section, which accelerated the bubble deformation and increased the probability of bubble breakup. The mixing of the bubbles and water due to high turbulent forces at the throat and the rapid deceleration as the flow reaches the diffuser divergent section had a significant effect on the diameter of the bubbles at the outlet.

Water flow rate $=8.21 \mathrm{~L} / \mathrm{min}$

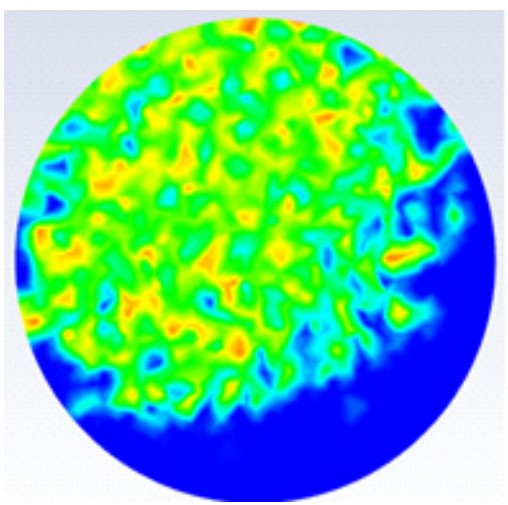

Air flow rate $=5 \times 10^{-2} \mathrm{~L} / \mathrm{min}$,

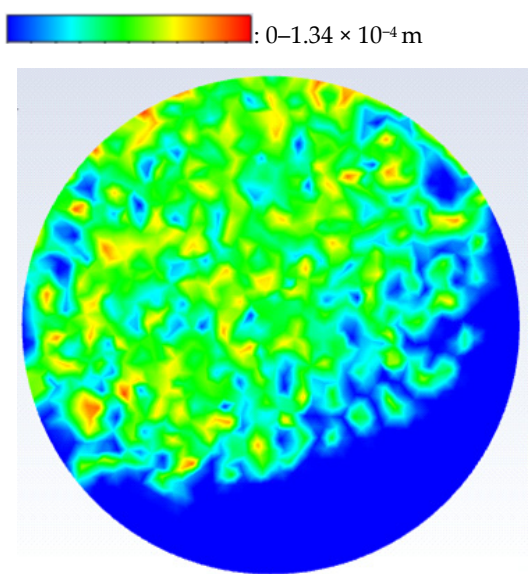

Water flow rate $=13.3 \mathrm{~L} / \mathrm{min}$

Air flow rate $=5 \times 10^{-2} \mathrm{~L} / \mathrm{min}$

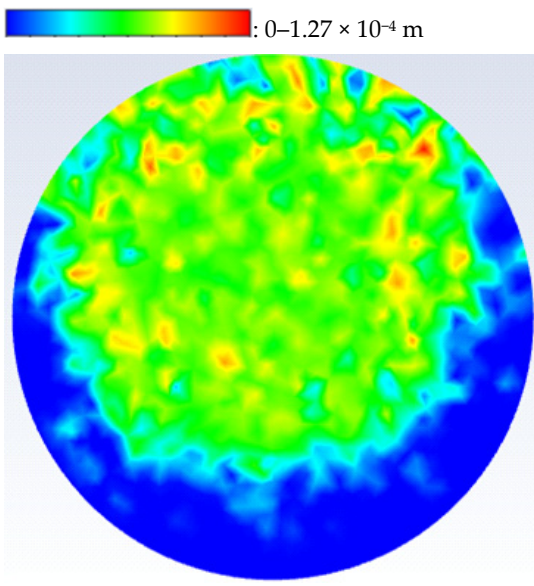

Air flow rate $=7.32 \times 10^{-3} \mathrm{~L} / \mathrm{min}$, $0-1.36 \times 10^{-4} \mathrm{~m}$

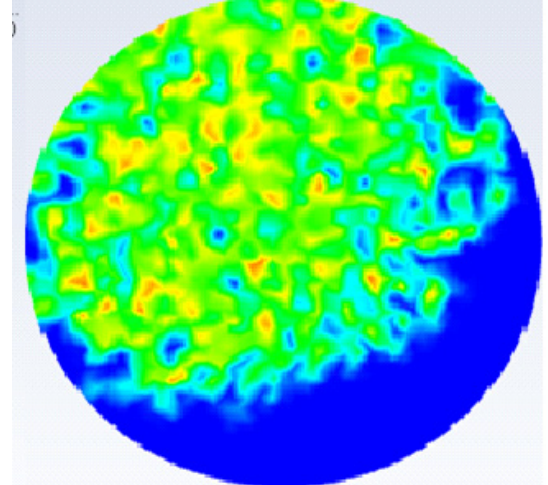

Air flow rate $=0.21 \mathrm{~L} / \mathrm{min}$,

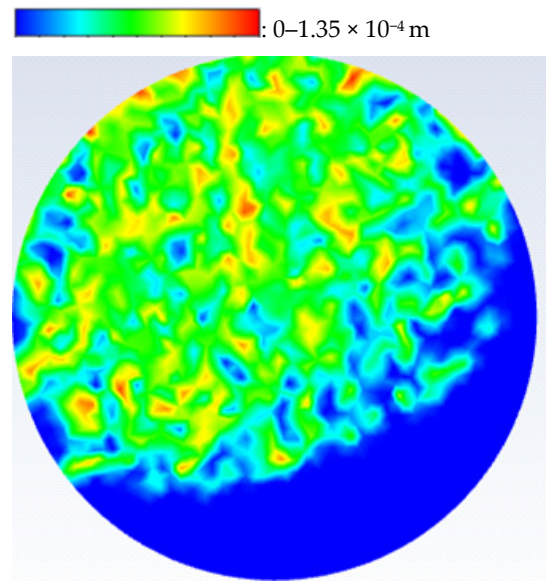

Air flow rate $=0.21 \mathrm{~L} / \mathrm{min}$,

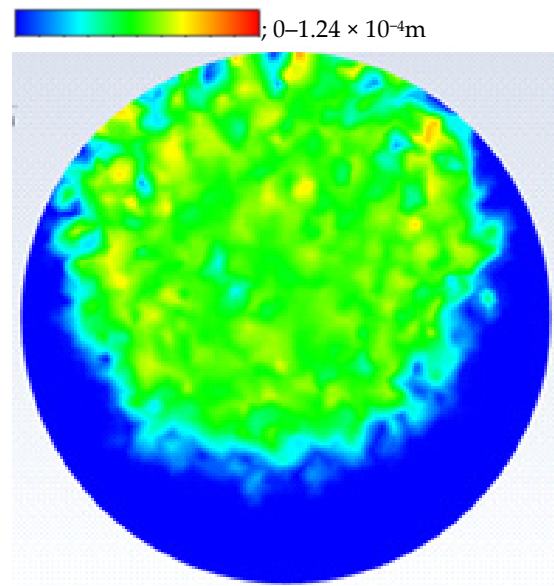

Air flow rate $=2.93 \times 10^{-2} \mathrm{~L} / \mathrm{min}$, $0-1.45 \times 10^{-4} \mathrm{~m}$

Figure 9. The contours for drop diameter distribution at the exit of the microbubble generator for cases of different water and air flow rates. 


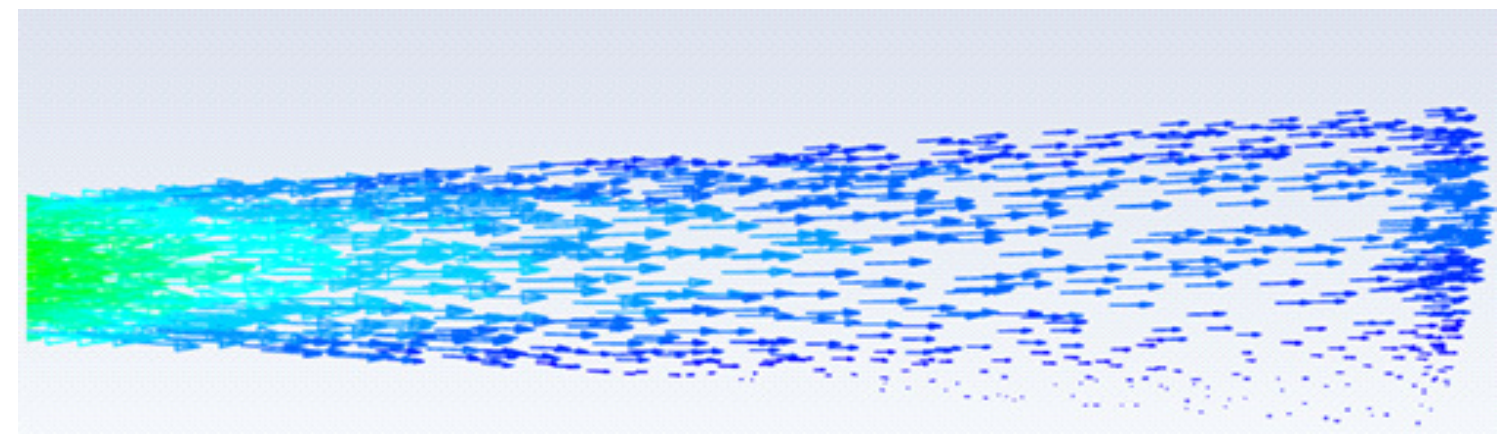

Water flow rate $=8.21 \mathrm{~L} / \mathrm{min}$, Air flow rate $=0.1 \mathrm{~L} / \mathrm{min}$,

$0-2.83 \times 10^{1} \mathrm{~m} / \mathrm{s}$

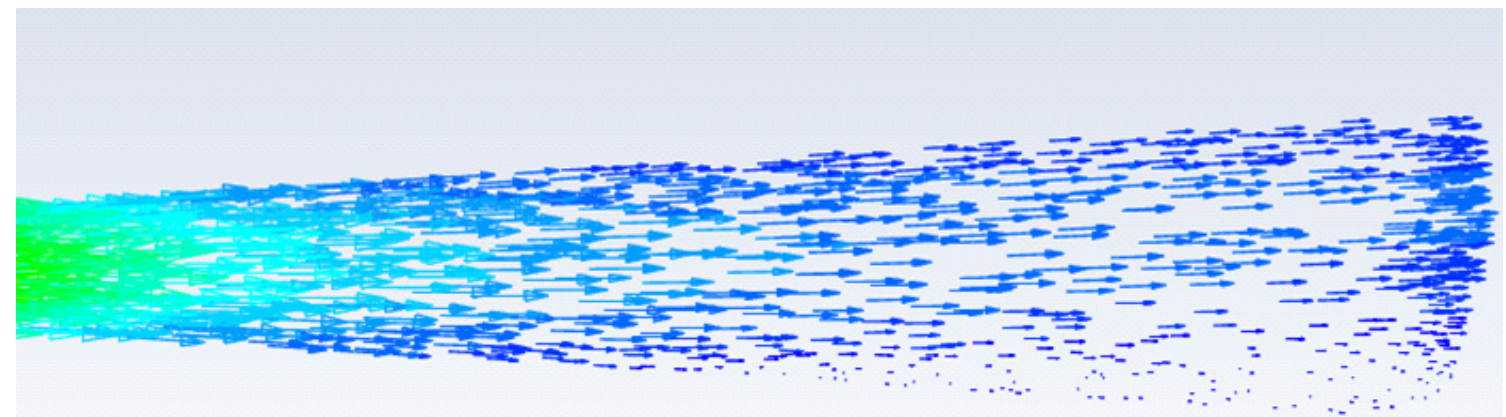

Water flow rate $=13.3 \mathrm{~L} / \mathrm{min}$, Air flow rate $=0.1 \mathrm{~L} / \mathrm{min}$,

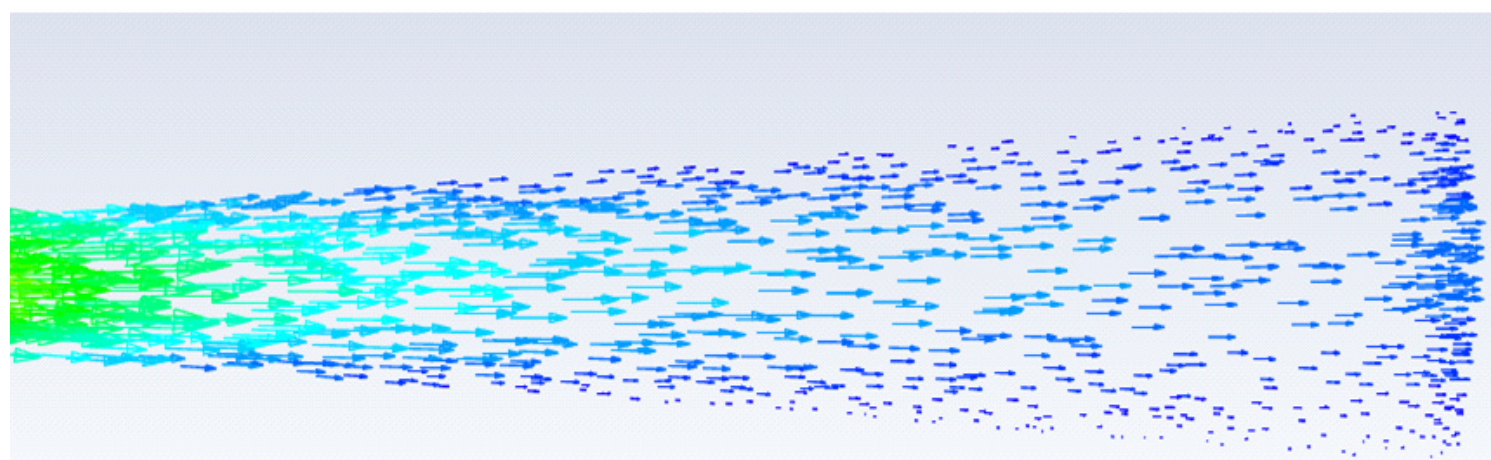

Water flow rate $=1.21 \mathrm{~L} / \mathrm{min}$, Air flow rate $=1.46 \times 10^{-3} \mathrm{~L} / \mathrm{min}$,

: 0-3.97 m

Figure 10. The velocity vectors for cases of different water and air flow rates.

\subsection{The Effect of Geometrical Parameters on Average Bubble Diameter and Bubble Diameter Distribution}

The bubble diameter distribution and the average diameter produced by Venturi are a function of a number of geometric parameters. Huang et al. [10] indicated that the parameters include the convergent angle $(\alpha)$, diffuser divergent angle $(\beta)$, throat length $(1)$, throat diameter $(d)$, outlet diameter $(D)$, and gas feeding hole diameter $\left(\mathrm{d}_{\mathrm{g}}\right)$. Their main conclusion is that throat length/throat diameter ratio and diverging angle play key roles in determination of the performance of a Venturi-type bubble generator. For the $1 / \mathrm{d}$ ratio, the results from Reichmann et al. [9] and Huang et al. [10] showed that bubble diameter reduced with higher $1 / \mathrm{d}$ ratio while the results from Unyaphan et al. [18] did not support 
this conclusion. For the diverging angle, Lee et al. [19] and compared the bubble diameter produced from five Venturi tubes with different diverging angles in the range of $15^{\circ}-45^{\circ}$. They found that increasing the diverging angle reduced the diameter of produced bubbles, except the cases of high liquid flow rates. Zhao et al. [20] conducted experiments with rectangular cross-section Venturi bubble generators with three diverging angles $\left(7.5^{\circ}, 10.0^{\circ}\right.$, and $12.5^{\circ}$ ) and their conclusion was very much similar to Lee et al. [19].

The published experimental data indicated that throat length/throat diameter ratio and diverging angle are the main parameters affecting the microbubble diameter. To gain better understanding of the effect of both parameters, CFD simulation was used to produce images (contours) to visualize the flow behavior within the Venturi microbubble generator for different values of both parameters.

\subsubsection{The Effect of Throat Length to Throat Diameter Ratios $(1 / \mathrm{d})$}

Three throat length to throat diameter ratios $(1 / \mathrm{d}=2,3.57$ and 7.5$)$ were modeled to see the effects with flow conditions remaining constant. The baseline case of $1 / \mathrm{d}=3.57$ was used as reference case in this investigation. The bubble diameter distributions from the simulation are given in Figure 11. The average bubble diameter was calculated at inlet, middle, and outlet of the diverging section for the three $1 / \mathrm{d}$ ratios and presented in Figure 12.

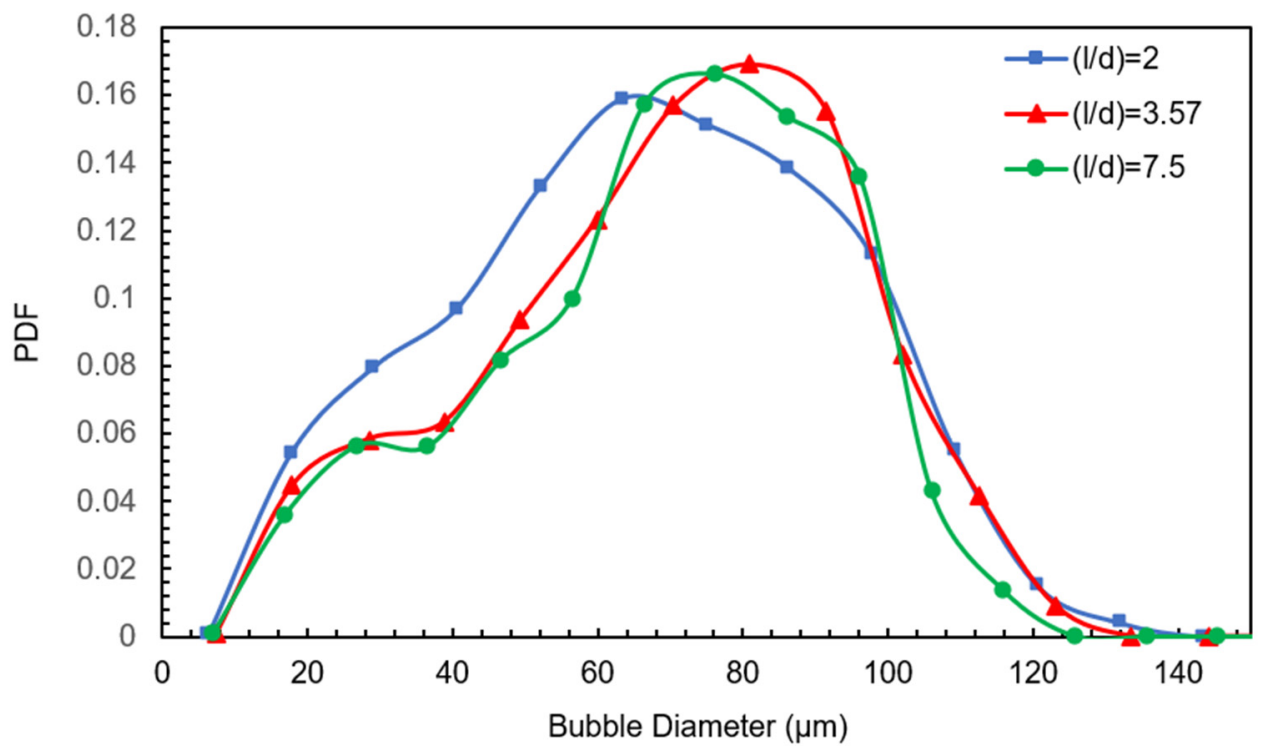

Figure 11. Distribution of bubble diameters at the outlet section of the diffuser for different $1 / \mathrm{d}$ ratios. (Water flow rate $=$ $8.21 \mathrm{~L} / \mathrm{min}$, air flow rate $=0.1 \mathrm{~L} / \mathrm{min}$ ).

From Figures 11 and 12, the results showed that throat length/throat diameter ratio had a small effect on the average bubble diameter. The data from Reichmann et al. [9] and Huang et al. [21] showed that smallest bubble produced from higher length throat/throat diameter ratios. The discrepancy between the present CFD results and literature may be attributed to the very high throat velocities ( $>3$ times) in present work compared to others, which reduced the effect of $1 / \mathrm{d}$ ratio on bubble diameter. Despite the same ratios not being tested, the lowest ratio did produce on average the smallest bubble diameter by a small margin. The contours of the bubble distribution at the outlet of the diffuser are given in Figure 13. It displays uneven distribution of bubbles across the outlet face on all tested ratios, which increased with higher $1 / d$ ratio. This suggests that $1 / d$ ratio less than 5 may be the practical value. 


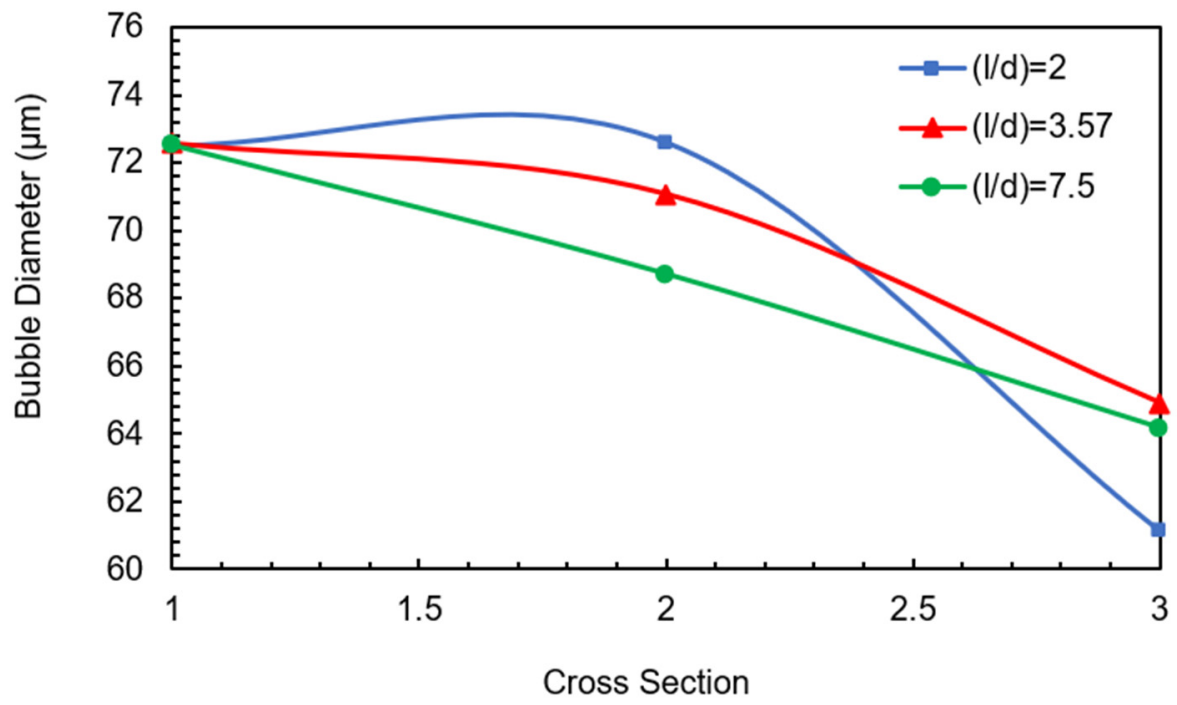

Figure 12. Effect of $1 / d$ ratio on averages bubble diameter at different axial locations (cross sections 1 , 2 , and 3 are the diffuser entry, midpoint and end, respectively). (Water flow rate $=8.21 \mathrm{~L} / \mathrm{min}$, air flow rate $=0.1 \mathrm{~L} / \mathrm{min}$ )
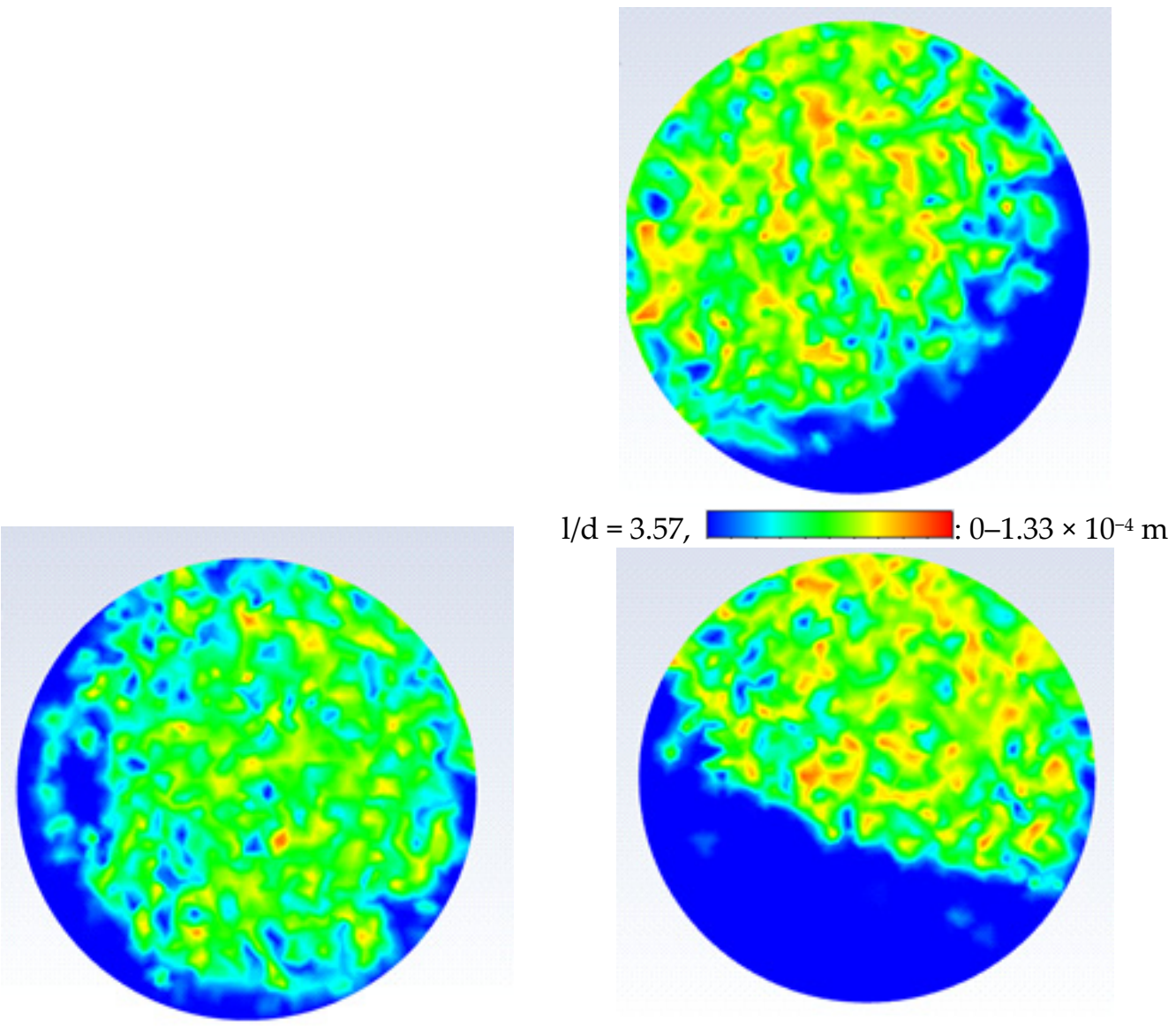

$1 / d=2$,

$0-1.5 \times 10^{-4} \mathrm{~m} \quad 1 / \mathrm{d}=7.5$

: $0-2 \times 10^{-4} \mathrm{~m}$

Figure 13. The contours of bubble distribution at the outlet section of the diffuser. (Water flow rate $=8.21 \mathrm{~L} / \mathrm{min}$, air flow rate $=0.1 \mathrm{~L} / \mathrm{min})$. 


\subsubsection{Effect of Diffuser Divergent Angle}

The effect of the diffuser divergent angle was also tested to increase awareness of the change of this geometrical property. Angles of $2.13^{\circ}, 4.26^{\circ}, 8.52^{\circ}$, and $17.04^{\circ}$ were tested by changing only the outlet diameter of the baseline Venturi-type microbubble generator. The pdf distribution of the bubble diameter at the outlet section from the model for different diffuser divergent angles are given in Figure 14. The evolution of the average bubble with axial direction was also calculated and presented in Figure 15.

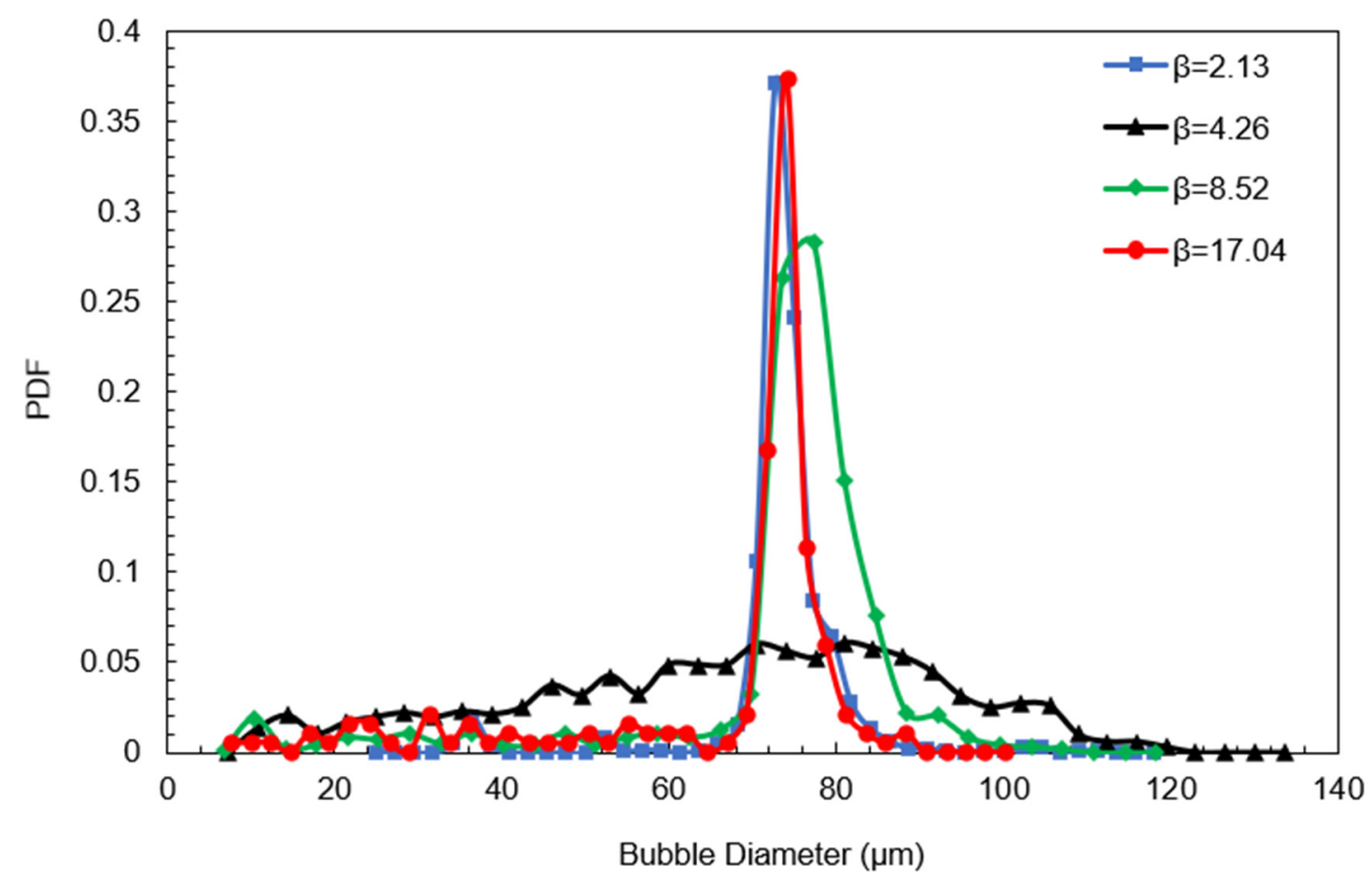

Figure 14. The pdf distribution of the bubble diameter at the outlet section of the diffuser. (Water flow rate $=8.21 \mathrm{~L} / \mathrm{min}$, air flow rate $=0.1 \mathrm{~L} / \mathrm{min})$.

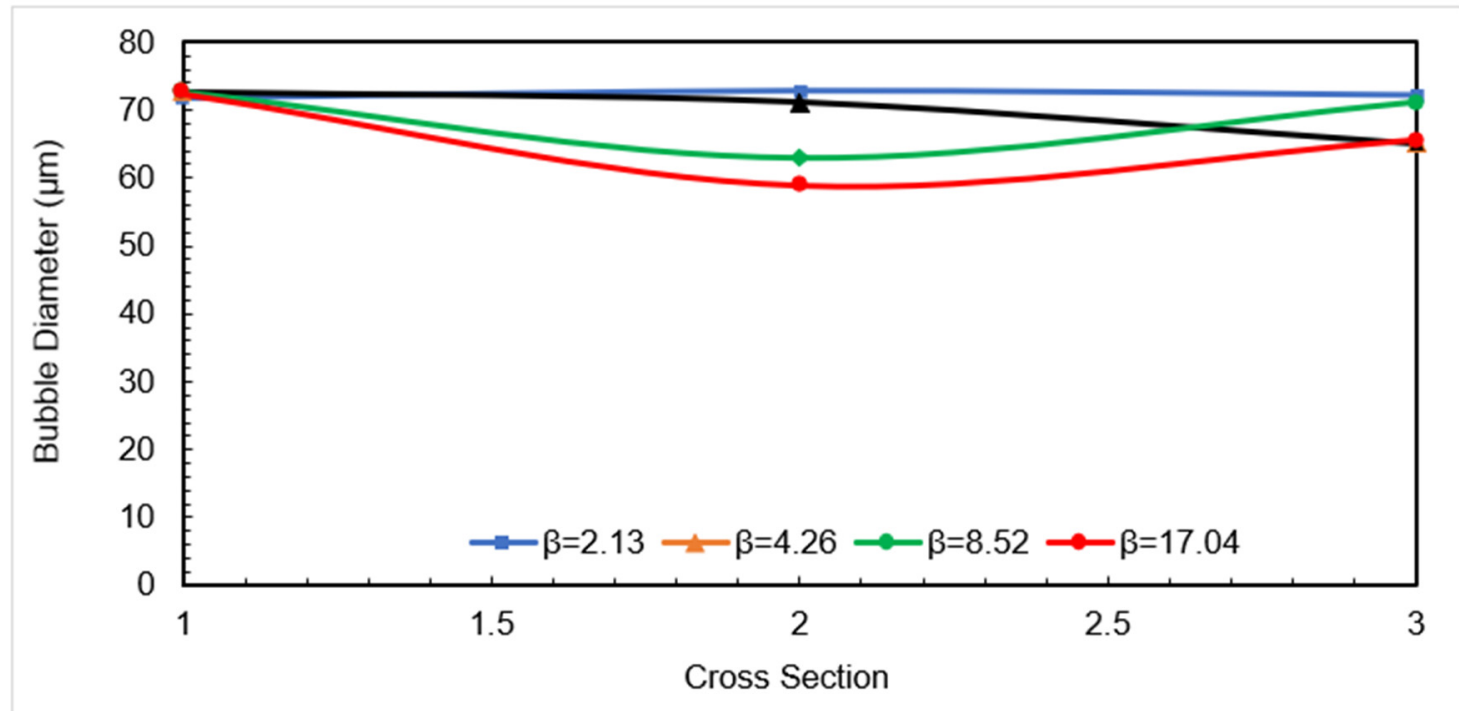

Figure 15. Effect of diverging angle on evolution of average bubble diameter at different axial locations (cross sections 1,2 , and 3 are the diffuser entry, midpoint, and end, respectively). (Water flow rate $=8.21 \mathrm{~L} / \mathrm{min}$, air flow rate $=0.1 \mathrm{~L} / \mathrm{min}$ ). 
The results from the model predictions indicated that the effect of diverging angle at these boundary conditions was small as there were no significant differences between the average bubble diameters at the diffuser outlet of all tested angles. A diffuser angle of 4.26 degrees did however produce the smallest average bubble diameter by a small margin. Contour plots of the bubble distribution suggest that greater diffuser angles create non-uniform distribution of bubbles at the diffuser outlet as in Figure 16. Further investigation into the bubble distribution at the outlet of the diffuser resulted in instances of reversed flow at the outlets in the lower region of the diffuser as the angle was increased as in Figure 17. This is likely the cause of bubble formations occurring in the upper region of the diffuser.
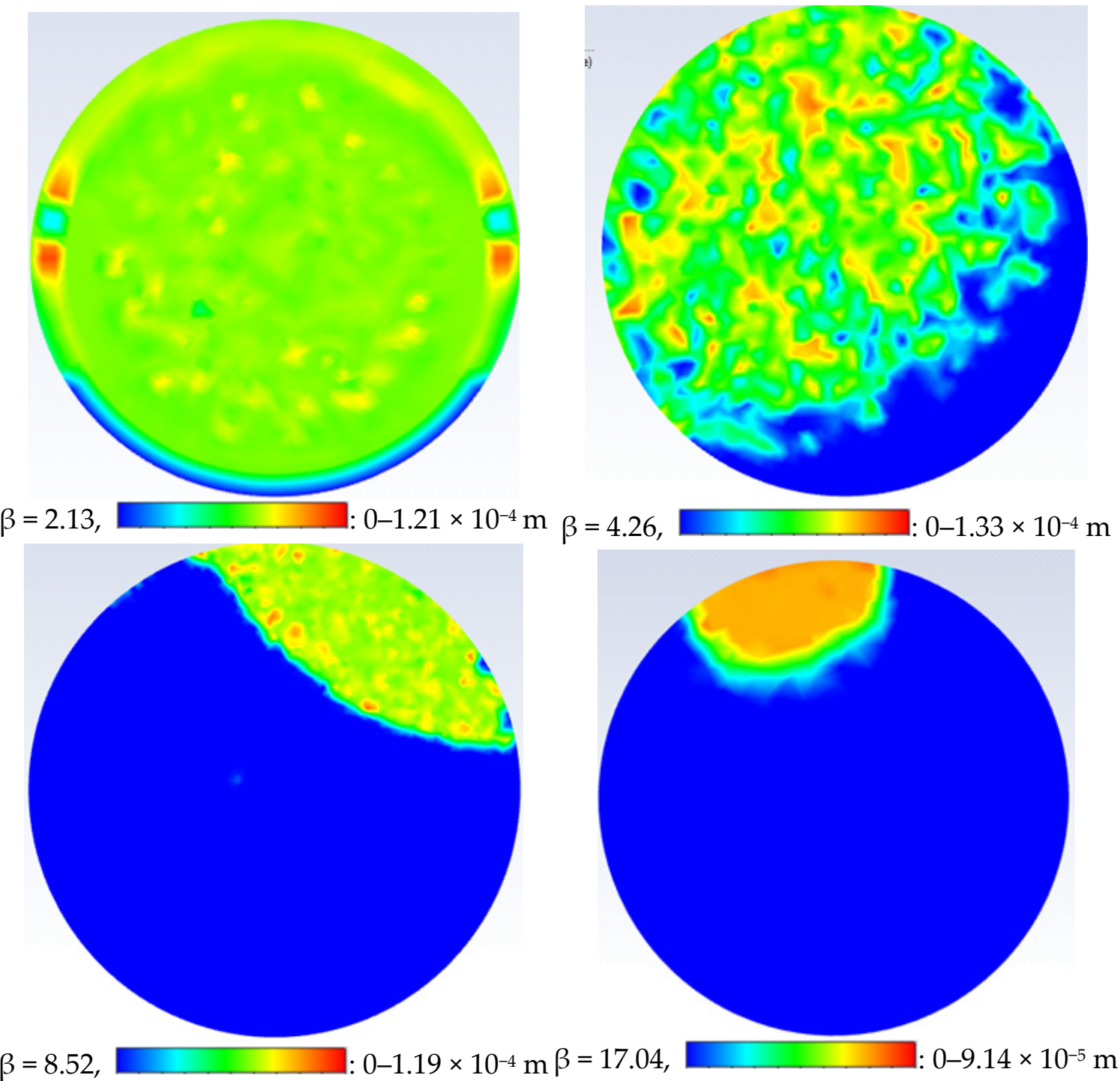

Figure 16. The contours of bubble distribution at the outlet section of the diffuser. (Water flow rate $=8.21 \mathrm{~L} / \mathrm{min}$, air flow rate $=0.1 \mathrm{~L} / \mathrm{min})$. 

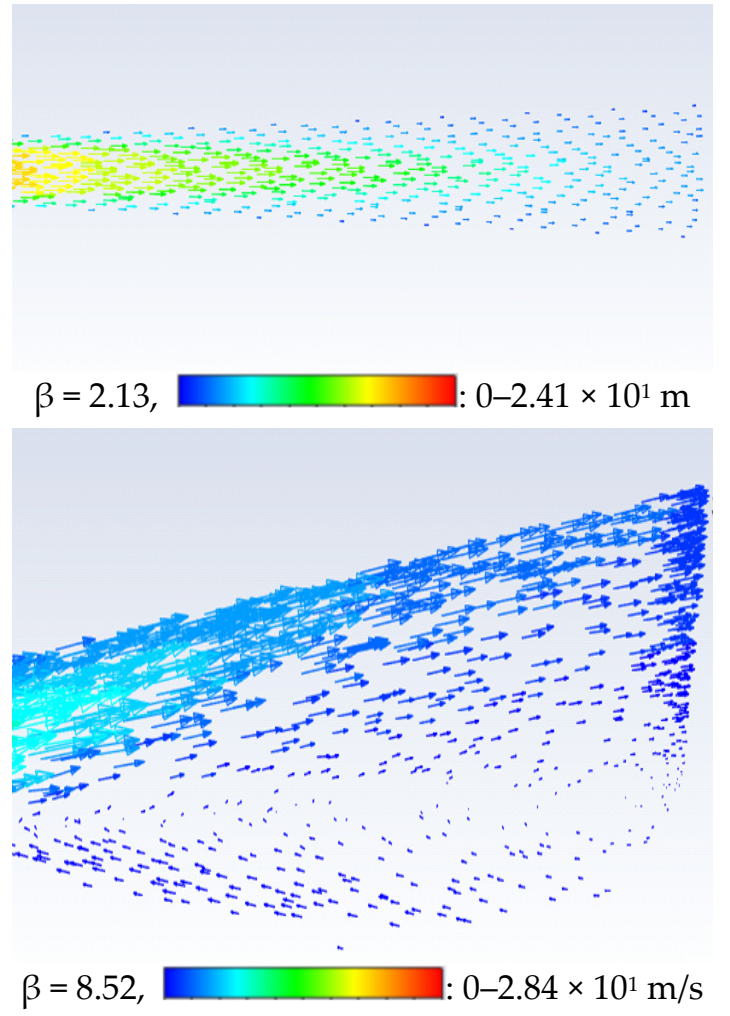
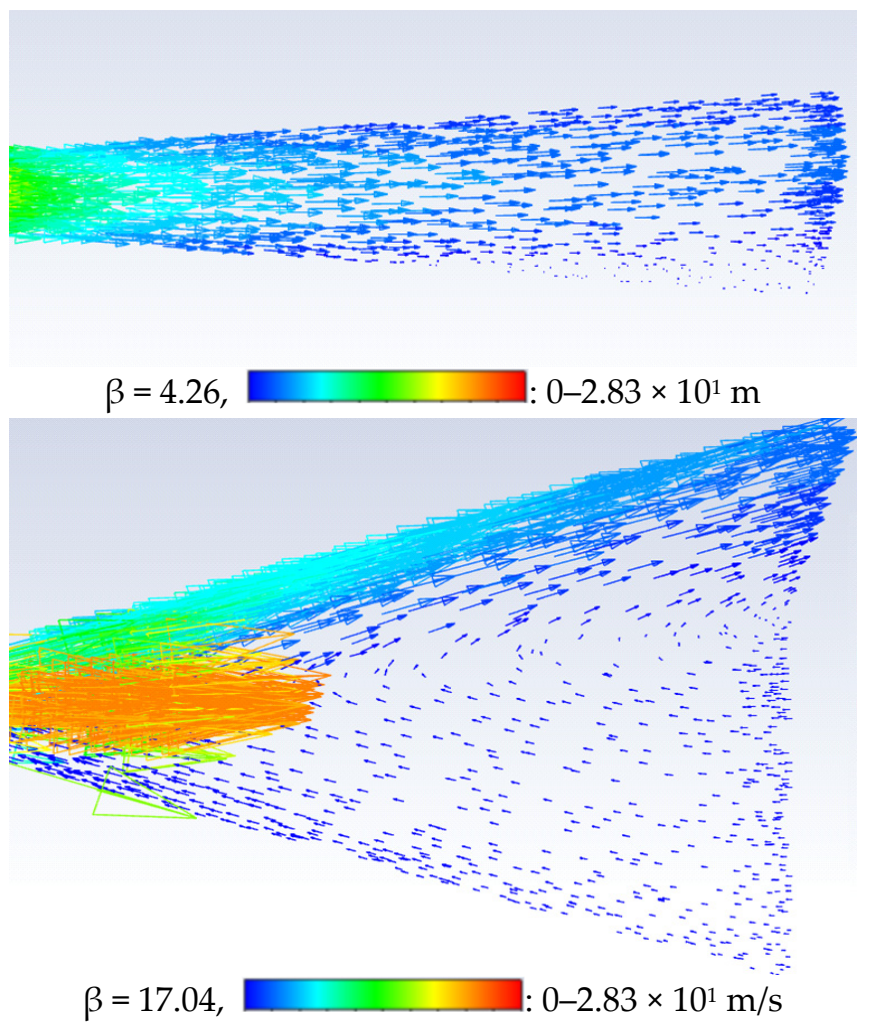

Figure 17. The velocity vectors for different diverging angles. (Water flow rate $=8.21 \mathrm{~L} / \mathrm{min}$, air flow rate $=0.1 \mathrm{~L} / \mathrm{min}$ ).

\section{Conclusions}

Although there are many methods of producing microbubbles, air injection combined with a Venturi-type geometry provides one of the simplest and most practical solutions. Then, experimental data were collected for a design using different combinations of water and air flow rates. The experimental data were used to validate a CFD model generated in Ansys Fluent. Then, the model was used to study the effect of throat length/throat diameter ratio and diffuser divergent angle on the distribution of the generated bubbles and the average bubble diameter. The main conclusions can be summarized as:

1. It is evident that controlling a combination of flow parameters and geometry will allow good control over the range and average bubble diameters produced at the outlet. In particular, the water flow rate used has the greatest influence on the bubbles produced at the outlet out of all properties tested in this research.

2. The throat length/throat diameter ration and diffuser divergent angle had a minor effect on bubble diameter distribution and average bubble diameter for the range of the throat water velocities used in this study $(22-35 \mathrm{~m} / \mathrm{s})$ compared to the low velocity used in literature $(>10 \mathrm{~m} / \mathrm{s})$.

3. Reversed flow in the divergent section of the microbubble generator due to the pressure gradients in this region were a significant factor in bubble breakup, further work into the bubble break up mechanisms would be useful to control the bubble sizing further.

4. The contours of the bubble distribution at outlet and the velocity vectors in the diffuser section present a detailed picture of the flow behavior and help to select the optimum design to use.

Author Contributions: D.A.W., literature review, CFD and original draft preparation, K.P., literature review, experimental measurements and image analysis, P.B.G., Conceptualization review and editing, F.H., Conceptualization, writing, review and editing, All authors have contributed in reviewing and 
editing the paper after submission to the journal. All authors have read and agreed to the published version of the manuscript.

Funding: This research received no external funding.

Conflicts of Interest: The authors declare no conflict of interest.

\section{References}

1. Tao, D. Role of Bubble Size in Flotation of Coarse and Fine Particles-A Review. Sep. Sci. Technol. 2005, 39, 741-760. [CrossRef]

2. Agarwal, A.; Ng, W.J.; Liu, Y. Principle and applications of microbubble and nanobubble technology for water treatment. Chemosphere 2011, 84, 1175-1180. [CrossRef]

3. Gomez-Flores, A.; Solongo, S.K.; Heyes, G.W.; Ilyas, S.; Kim, H. Bubble-particle interactions with hydrodynamics, XDLVO theory, and surface roughness for flotation in an agitated tank using CFD simulations. Miner. Eng. 2020, 152, 106368. [CrossRef]

4. Chowdhurri, A.; Talib, A.; Yahya, K. A review on marine shrimp aquaculture production trend Malaysia and the world perspective. In Proceedings of the International Fisheries Symposium 2012, Can Tho University, Cab Tho, Vietnam, 6-8 December 2012.

5. Dijkmans, P.; Juffermans, L.; Musters, R.; Van Wamel, A.; Cate, F.T.; Van Gilst, W.; Visser, C.; De Jong, N.; Kamp, O. Microbubbles and ultrasound: From diagnosis to therapy. Eur. J. Echocardiogr. 2004, 5, 245-256. [CrossRef] [PubMed]

6. Takahashi, M.; Kawamura, T.; Yamamoto, Y.; Ohnari, H.; Himuro, S.; Shakutsui, H. Effect of Shrinking Microbubble on Gas Hydrate Formation. J. Phys. Chem. B 2003, 107, 2171-2173. [CrossRef]

7. Basso, A.; Hamad, F.; Ganesan, P. Effects of the geometrical configuration of air-water mixer on the size and distribution of microbubbles in aeration systems. Asia-Pac. J. Chem. Eng. 2018, 13, e2259. [CrossRef]

8. Lijun, W. Gas-liquid numerical simulation on micro-bubble generator and optimization on the nozzle-to-throat spacing. Asia-Pac. J. Chem. Eng. 2015, 10, 893-903.

9. Reichmann, F.; Varel, F.; Kockmann, N. Energy Optimization of Gas-Liquid Dispersion in Micronozzles Assisted by Design of Experiment. Processes 2017, 5, 57. [CrossRef]

10. Huang, J.; Sun, L.; Liu, H.; Mo, Z.; Tang, J.; Xie, G.; Du, M. A review on bubble generation and transportation in Venturi-type bubble generators. Exp. Comput. Multiph. Flow 2020, 2, 123-134. [CrossRef]

11. Li, M.; Bussonnière, A.; Bronson, M.; Xu, Z.; Liu, Q. Study of Venturi tube geometry on the hydrodynamic cavitation for the generation of microbubbles. Miner. Eng. 2019, 132, 268-274. [CrossRef]

12. Basso, A.; Hamad, F.; Ganesan, P. Initial Results from the Experimental and Computational Study of Microbubble Generation. In Proceedings of the 4th World Congress on Momentum, Heat and Mass Transfer; Avestia Publishing: Orléans, ON, Canada, 2019.

13. Rhody, H.; Carlson, C. Lecture 10: Hough Circle Transform. 2005. Available online: https://www.cis.rit.edu/class/simg782 /lectures/lecture_10/lec782_05_10.pdf (accessed on 6 July 2020).

14. ANSYS Fluent. 2020. Available online: http:/ / www.ansys.com/Industries/Academic/Tools/Citations (accessed on 6 July 2020).

15. Zhou, J.-S.; Luo, Z.-Y.; Gao, X.; Ni, M.-J.; Cen, K.-F. Effect of particle loading ratio on heat transfer enhancement in a gas-solid suspension cross flow. J. Zhejiang Univ. Sci. A 2002, 3, 381-386. [CrossRef]

16. Stakic, M.; Zivkovic, G.; Sijercic, M. Numerical analysis of discrete phase induced effects on a gas flow in a turbulent two-phase free jet. Int. J. Heat Mass Transf. 2011, 54, 2262-2269. [CrossRef]

17. Huang, J.; Sun, L.; Mo, Z.; Liu, H.; Du, M.; Tang, J.; Bao, J. A visualized study of bubble breakup in small rectangular Venturi channels. Exp. Comput. Multiph. Flow 2019, 1, 177-185. [CrossRef]

18. Unyaphan, S.; Tarnpradab, T.; Takahashi, F.; Yoshikawa, K. Improvement of tar removal performance of oil scrubber by producing syngas microbubbles. Appl. Energy 2017, 205, 802-812. [CrossRef]

19. Lee, C.H.; Choi, H.; Jerng, D.-W.; Kim, D.E.; Wongwises, S.; Ahn, H.S. Experimental investigation of microbubble generation in the venturi nozzle. Int. J. Heat Mass Transf. 2019, 136, 1127-1138. [CrossRef]

20. Zhao, L.; Sun, L.C.; Mo, Z.Y.; Du, M.; Huang, J.; Bao, J.J.; Tang, J.G.; Xie, G. Effects of the divergent angle on bubble transpor-tation in a rectangular Venturi channel and its performance in producing fine bubbles. Int. J. Multiph. Flow 2019, 114, 192-206. [CrossRef]

21. Huang, J.; Sun, L.; Du, M.; Liang, Z.; Mo, Z.; Tang, J.; Xie, G. An investigation on the performance of a micro-scale Venturi bubble generator. Chem. Eng. J. 2020, 386, 120980. [CrossRef] 